\title{
Ecological Effects on Female Bill Color Explain Plastic Sexual Dichromatism in A Mutually- Ornamented Bird
}

\section{Rita Freitas}

University of Porto

Cristiana Marques

University of Porto

Gonçalo C. Cardoso

University of Porto

Sandra Trigo ( $\nabla$ strigo@cibio.up.pt)

University of Porto

\section{Research Article}

Keywords: sexual ornamentation, social ornamentation, sexual dichromatism, plasticity, sexual selection.

Posted Date: March 5th, 2021

DOI: https://doi.org/10.21203/rs.3.rs-271112/v1

License: (c) This work is licensed under a Creative Commons Attribution 4.0 International License.

Read Full License

Version of Record: A version of this preprint was published at Scientific Reports on July 22nd, 2021. See the published version at https://doi.org/10.1038/s41598-021-93897-z. 


\section{Abstract}

Sex differences in ornamentation are common and, in species with conventional sex roles, are generally thought of as fixed, due to stronger sexual selection on males. Yet, especially in gregarious species, ornaments can also have non-sexual social functions, raising the possibility that observed sex differences in ornamentation are not fixed. For example, females may invest in costly ornamentation more plastically, to protect body and reproductive ability in more adverse ecological conditions. We tested this hypothesis with experimental work on the mutually-ornamented common waxbill (Estrilda astrild), supplementing their diets either with pigment (lutein, a carotenoid) or non-pigment (vitamin E) antioxidants, or alleviating winter cold temperature. We found that both lutein and vitamin $\mathrm{E}$ supplementation increased red bill colour saturation in females, reaching the same mean saturation as males, which supports the hypothesis that female bill colour is more sensitive to environmental or physiological conditions. The effect of vitamin E, a non-pigment antioxidant, suggests that carotenoids were released from their antioxidant functions. Alleviating winter cold did not increase bill color saturation in either sex, but increased the stability of female bill color over time, suggesting that female investment in bill color is sensitive to cold-mediated stress. Together, results show that waxbill bill sexual dichromatism is not fixed. Instead, sexual dichromatism can be modulated, and even disappear completely, due to ecology-mediated plastic adjustments in female bill color.

\section{Introduction}

In animals with conventional sex roles, reproduction in females is limited by their physiology, while males can differ greatly in reproductive success depending on the number of mates and fertilizations and, thus, experience very strong sexual selection ${ }^{1,2}$. This explains why it is common that sexual ornamentation is present only in males or, in mutually-ornamented species, that males are the more ornamented sex ${ }^{1,3,4}$. Because of this sex difference in the strength of sexual selection, sex differences in ornamentation are largely thought to be fixed due to genetic differences between males and females (hereafter, genetically fixed differences).

Especially in gregarious animals, ornamentation can be involved in several aspects of non-sexual social selection, such as competition among group members for resources or social hierarchy ${ }^{5,6}$. Unlike sexual selection, social selection in species with conventional sex roles need not to be stronger for males than females. Therefore, some sex differences in ornamentation may not be fixed. The phenomenon of plastic sex differences in ornamentation, i.e., those differences that result from sex differences in phenotypic plasticity, is poorly documented or investigated in species with conventional sex roles. Some examples were nonetheless reported, such as the ornamental bill color of some birds, which can change plastically $7,8,9,10$ and where changes in color appear affected by ecology or physiology differently in females and in males ${ }^{11,12,13}$.

Plastic sex differences in ornamentation are predicted to evolve when ornamentation benefits both sexes, but females and males differ in whether or how they benefit from adjusting ornamentation in response to 
external or physiological conditions ${ }^{14,15}$. Ornamentation is often costly, and investing in ornaments may imply trade-offs with investing in physiological functions ${ }^{16}$. For example, investing in carotenoid-based color ornaments may compromise allocating carotenoids for antioxidant functions ${ }^{17,18}$, and may be limited by individual differences in coping with oxidative stress ${ }^{19}$, immunocompetence ${ }^{20}$ or parasites ${ }^{21}$. Since investment in ornamentation can imply trade-offs with other functions, sex differences in lifehistory could cause females and males to adjust investment in ornaments differently, giving rise to sex differences in the phenotypic plasticity of ornamentation.

Studying bill color in common waxbills (Estrilda astrild), a gregarious bird with conventional sex roles ${ }^{22}$, Funghi et al. ${ }^{13}$ suggested that female ornamentation may be more sensitive to the quality of environmental conditions, perhaps because females need to balance investment in ornamentation with maintaining physiological condition for reproduction, and also suggested that female adjustments investing in ornaments may explain plastic sex differences in ornamentation. Males, on the contrary, perhaps because of not bearing a large physiological cost of reproduction, would invest in ornamentation across a wider range of ecological conditions. This hypothesis is partly supported by three observations on common waxbill ornamentation:

1. Although, on average, males are more ornamented than females, with more saturated red color in the bill and plumage (see Figure $1 \mathrm{~F}$ in ${ }^{23}$ ), the sex difference in bill color disappears in ecologically and energetically favorable conditions (ad libitum food and mild temperatures ${ }^{13,24}$.

2. Bill color saturation is not a badge of status signaling social dominance, since neither bill color nor changes in color reflect aggressiveness or, as a consequence, dominance ${ }^{13}$, see also 25 .

3. Instead, a correlational test found that changes in the bill color saturation of females, but not males, were positively related to fluctuations in temperature, especially night temperatures that can pose the greatest energetic stress to small birds ${ }^{13}$.

These observations suggest that female and male waxbills do not differ in the maximum bill color saturation that they express, but that females plastically adjust investment in bill color depending on the quality of environmental conditions. If correct, this explanation for sexual dichromatism, based on female plasticity in ornamentation, departs strongly from the common view that sex differences in ornamentation are mostly genetically fixed ${ }^{1,2}$. However, the critical observation that female bill color saturation responds to environmental quality (observation 3 , above) is only correlational, and needs experimental confirmation.

Here, we use female and male common waxbills in experiments that manipulate either diet or temperature, to test how these environmental conditions affect investment in bill color saturation. We study bill color saturation because it can reflect carotenoid availability ${ }^{26}$, because saturation is a color parameter showing sexual dichromatism in waxbill bills ${ }^{23}$, and because previous observations suggest that sex differences in color saturation change depending on the environment ${ }^{13,24}$. 
First, we manipulated dietary availability of a carotenoid and a non-carotenoid antioxidant: lutein and vitamin $\mathrm{E}$, respectively. Lutein is the main dietary carotenoid found in waxbills blood ${ }^{27}$, and we hypothesize that increasing its availability allows more investment in bill color saturation. Vitamin $\mathrm{E}$ is a powerful non-colorant antioxidant ${ }^{28}$, and increasing its availability can be hypothesized to have positive effects on coloration (e.g., Larus michahellis ${ }^{29}$ ) by alleviating the use of carotenoid pigments for antioxidant functions ${ }^{30}$. We predict that these effects should be more pronounced in females, if females are the sex whose investment in ornamentation is most affected by environmental conditions and availability of resources. Second, we manipulated temperature during winter, to test if alleviating the energetic stress of winter cold, especially cold nights, facilitates investment in bill color. Again, we predict that effects of protecting from cold should be more pronounced in females, if female investment in bill color is most affected by environment-mediated energetic constrains.

\section{Results}

\section{Diet experiment}

For female bill color saturation, we found a significant interaction between diet treatment (control, lutein and vitamin $E$ ) and time point (before vs. after the diet manipulation; $F_{2,66}=3.37, P=0.04$, Figure $1 A$; effects of treatment and time point: $F_{2,66}=1.9, P=0.15$, and $F_{1,66}=2.91, P=0.09$, respectively), indicating that changes in bill color saturation differed between treatments. Post hoc tests showed that changes in female bill color saturation differed between the control treatment and lutein supplementation (interaction effect: $F_{1,44}=4.71, P=0.035$; Table S1) and not vitamin $E$ supplementation (interaction effect $F_{1,44}=0.77, P=0.77 ;$ Table S1). We found no effects of the diet manipulation in male bill color (interaction between treatment and time point: $F_{2,60}=0.05, P=0.86$, Figure $1 B$; effects of treatment and time point: $F_{2,60}=1.88, P=0.16$, and $F_{1,60}=0.03, P=0.86$ ).

Changes in body weight also did not differ significantly between diet treatments in females (interaction between treatment and time point: $F_{2,65}=0.22, P=0.80$; effects of treatment and time point: $F_{2,65}=0.16$, $P=0.85$ and $F_{1,65}=2.82, P=0.10$ ) nor in males (interaction: $F_{2,60}=0.10, P=0.91$; effects of treatment and time point $F_{2,60}=0.02, P=0.98$, and $F_{1,60}=0.70, P=0.41$ ).

It is possible that finding an effect of lutein, but not of vitamin $\mathrm{E}$, on changes in female bill color (Figure 1A) could be due to carry-over effects because, while the lutein treatment followed the control diet, the vitamin $\mathrm{E}$ treatment often followed the lutein treatment (and therefore its initial bill color measurement could already be elevated). To test effects of the diet treatment in a manner that is more robust to carryover effects, we compared initial measurements of bill color saturation, before any treatment (grey bars in Figure 2), with measurements after each diet-supplementation treatments (orange and green bars in Figure 2). We found that bill color saturation differed significantly in females $\left(F_{2,33}=9.25, P=0.001\right.$; Table S2). Pairwise post-hoc comparisons with the measurements before any treatment showed that bill color saturation was higher in the lutein $\left(F_{1,22}=10.59, P=0.004\right)$ and the vitamin $E$ treatments $\left(F_{1,22}=\right.$ 
$9.62, P=0.005$; Figure $2 A)$. Again we found no effects of the diet treatments on male bill color saturation $\left(F_{2,30}=0.80, P=0.46 ;\right.$ Figure $\left.2 B\right)$.

\section{Temperature manipulation}

Changes in feeding differed between the two temperature treatments $(t=-6.64 ; N=6$ cages; $P=0.003)$, with birds in the cold-hot treatment decreasing feeding and birds in the hot-cold treatment increasing feeding (Figure $3 \mathrm{~A}$ ). Changes in body weight did not differ between the cold-hot and hot-cold treatments $(t=0.73 ; N=23$ birds; $P=0.48 ;$ Figure $3 B)$.

Changes in bill color saturation from the first 4 weeks to the last 4 weeks of the temperature manipulation experiment, using data from the entire 4-week periods, did not differ between the cold-hot and the hot-cold treatments in females $(t=-0.40 ; N=11$ birds; $p=0.70$; white bars in Figure $4 A)$ nor in males $(t=-1.14 ; N=$ 12 birds; $p=0.28$; black bars in Figure $4 A$ ). In case bill color takes a long time adjusting to temperature, we repeated this comparison using only data from the last 2 weeks of each 4-week period of temperature manipulation. Changes in female bill color saturation in the cold-hot treatment were now ca. 4 times higher than in the hot-cold treatment, but among-individual variation in these color changes was large and the difference between treatments was non-significant $(t=1.20 ; N=11 ; P=0.26$; white bars in Figure 4B). In males, the extent of bill color changes did not differ in the cold-hot and the hot-cold treatments $(\mathrm{t}=$ $0.01 ; N=12 ; P=0.99$; black bars in Figure 4B).

Within-individual fluctuation in female bill color, computed as the standard deviation of color saturation in each 4-week period, tended to decrease in the cold-hot treatment and to slightly increase in the hot-cold treatment, and the difference between treatments was significant $(\mathrm{t}=-2.54 ; \mathrm{N}=11$ birds; $\mathrm{P}=0.03$, white bars in Figure 4C). In males, changes in the extent of fluctuations in bill color did not differ between treatments $(t=0.17 ; N=12$ birds; $P=0.87$; black bars in Figure $4 C)$.

\section{Discussion}

Results from both our experiments support the hypothesis that female bill color is more sensitive to environmental conditions than male bill color. While we found no effects of lutein- or vitamin $E$ supplementation on male bill color saturation, female bill color increased with lutein supplementation and, compared to color saturation prior to any diet manipulation, also with vitamin E supplementation. In the temperature experiment, we again found no effects on male bill color saturation or on its stability over time. In females, while we also found no differences in mean bill color, bill color saturation became more stable when increasing winter temperature compared to when decreasing temperature, suggesting that female bill color is sensitive to temperature-mediated energetic stress.

Previous experiments with different species have shown that dietary carotenoid supplementation can increase the expression of carotenoid-based color ornamentation in bills e.g.3,11,31,32, and other bare

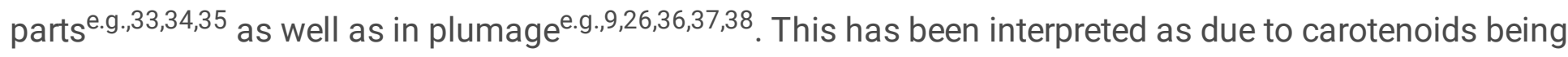
obtained exclusively from the diet (and not synthesized by animals ${ }^{39}$ ), which could limit carotenoid 
availability for coloration 40,41 , but see 42 , especially because carotenoids may be required for different functions, including pigmentation and antioxidant functions ${ }^{18,43,44}$, but see 45 . Similarly to work on other species, we found that carotenoid (lutein) supplementation in the diet can enhance the expression of carotenoid-based ornamentation in waxbills. Interestingly, we found this effect of carotenoid supplementation on bill color only in females, and not in males, providing experimental evidence for the suggestion that, in the common waxbill, female investment in ornamentation is more sensitive to environmental conditions than male investment in ornamentation ${ }^{13}$. As a consequence of this sexspecific effect, the bill sexual dichromatism normally observed in waxbills ${ }^{23,24}$ and observed here at the onset of the experiment (grey bars in Figure 2), disappeared after dietary carotenoid supplementation (orange bars in Figure 2). This shows that bill sexual dichromatism in the common waxbill is plastic, and its plasticity can be mediated by ecological effects on female bill color. To our knowledge, only one other study on a mutually-ornamented species, the black-legged kittiwake (Rissa tridactyla), reported a sexspecific effect of carotenoid supplementation on sexual ornamentation: carotenoid supplementation was associated with redder carotenoid-based color in the gape and tongue of females, but not males ${ }^{46}$ (see also ${ }^{47}$ for a study in chicks of the common tern, Sterna hirundo).

We also found evidence that dietary supplementation of vitamin $\mathrm{E}$, a non-pigmentary antioxidant, enhanced the expression of bill color saturation, again in females and not males. Vitamin $E$ is the main lipophilic antioxidant in animals, like carotenoids it is only acquired from the diet, and its abundance can significantly affect the antioxidant capacity of individuals and affect immune protection ${ }^{28,48}$. Finding that vitamin E supplementation can increase carotenoid-based color ornamentation, which has been reported in other species as well (birds ${ }^{29,49,50}$; reptiles ${ }^{51} ;$ fish $^{52}$ ), supports the hypothesis that abundant non-pigment antioxidant molecules free carotenoids from antioxidant functions and make them available for coloration, such that carotenoid-based ornamentation could signal antioxidant capacity ${ }^{17,18,30}$. Again, finding an effect of vitamin E supplementation in female bill color, but not male, supports the hypothesis that female waxbills require better physiological conditions to invest in costly ornamentation, while males prioritize investment in ornamentation in worse conditions.

Our temperature manipulations, exposing waxbills to winter temperatures and then increasing temperature by ca. $6^{\circ} \mathrm{C}$, or vice-versa, were physiologically meaningful because alleviating winter cold was associated with less feeding early in the morning. Winter cold, especially during nights, is an important energetic stressor for small birds, but our waxbills had ad libitum food and there were no changes in body mass associated with the temperature treatments (nor with the previous diet treatments), indicating that experimental treatments were not damaging to their body condition. Based on results from a previous correlational study with waxbills ${ }^{13}$, we expected that higher temperatures increased investment in bill color saturation, at least in females. Earlier work with male zebra finches (Taeniopygia guttata) had also reported that exposure to cold diminish bill color saturation ${ }^{11}$.

Contrary to expectations, we found no significant effects of temperature manipulations on the mean bill color saturation of either female or male waxbills. When comparing bill color during the last 2 weeks of 
temperature manipulations, to allow more time for bill color to adjust to temperature, we did find that mean changes in female bill color saturation were much higher (ca. four-fold higher) when passing from ambient to warmer temperatures than in the reverse treatment, but among-individual variation in the extent of these changes was large and the difference was non-significant. The explanation for the different results here and in Funghi et al. ${ }^{13}$ or Eraud et al. ${ }^{11}$ is not clear. It may be related with the time of the year in which the different studies were conducted, since our experiments were made in winter and the previous correlational study with waxbills was conducted across spring and summer ${ }^{13}$. Spring and summer correspond to the breeding season of waxbills in this region ${ }^{53}$, which may alter various aspects of their biology. Or the different results may be due to the extent of temperature differences used, since we alleviated winter cold with a $6^{\circ} \mathrm{C}$ warming, while the range of natural temperature differences the previous correlational study was higher, and Eraud et al. ${ }^{11}$ also subjected experimental birds to a much higher temperature difference of $20^{\circ} \mathrm{C}$.

We did find, however, a positive effect of alleviating winter cold on female bill color, in the form of more stable bill color saturation. Repeated measurements of waxbill bill color show considerable fluctuation through time ${ }^{13}$, perhaps reflecting changing investment in color ornamentation. Since the avian bill is living tissue and its color may be condition-dependente.g. 7,11,10, fluctuations in color are expected to occur, for example, if challenges to individual conditions render them less able to sustain a stable investment in bill color. For example, energetic stress caused by cold temperatures can cause oxidative

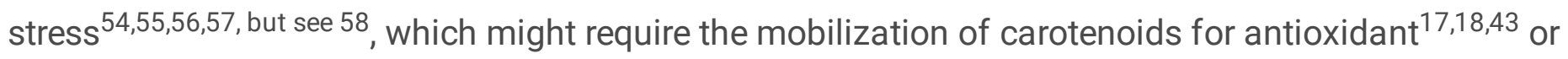
other physiological functions ${ }^{20,21}$. Therefore, bill color fluctuations may be symptomatic of unstable individual condition. We found that females passing from ambient to warmer temperatures reduced the degree of fluctuation in bill color saturation, as compared with the reverse treatment, but in males there were no effects of the temperature manipulation on color stability. This sex-specific effect of warmer temperatures on the stability of female bill color saturation supports the hypothesis that female bill color is more sensitive to environmental conditions, albeit in a different manner than suggested by previous correlational work ${ }^{13}$.

Taken together, our results provide experimental evidence for various sex-specific ecological effects on the bill color of common waxbills. Dietary enrichment with either a carotenoid or a non-carotenoid antioxidant increased female but not male bill color saturation, and protection from winter cold increased the stability of female but not male bill color saturation. It was previously suggested that a greater sensitivity to environmental conditions in female than male ornamentation could be explained by sex differences in life-history and in reproductive physiology ${ }^{13}$. Namely, in species with conventional sex roles, females carry the largest physiological burden of reproduction, including egg production, and therefore may prioritize maintaining physiological condition in detriment of investing in costly ornamentation. Conversely, males may prioritize allocating resources to ornamentation, even in suboptimal environmental or physiological condition, because they have the most to gain from sexual ornamentation, in the form of attracting mates and increasing paternity rates. According to this view, bill color in American goldfinches (Spinus tristis) was found to reflect individual differences in female 
immune function but not in males, who consistently invest in bill coloration irrespective of immune function ${ }^{12}$, and a recent field study with pied flycatchers (Ficedula hypoleuca) found that changes in female but not male plumage ornaments were affected by climate during breeding, such that cold and rainy breeding seasons decreased female ornamentation, likely reflecting a greater cost of breeding in those years ${ }^{59}$.

The ecology-mediated changes in the bill color of female waxbills that we showed here strongly affect the extent of sexual dichromatism, and can go as far as eliminating the sexual dichromatism that is usually observed in this species ${ }^{23,24}$. This finding departs from the usual view that, in species with conventional sex roles, sex differences in ornamentation are genetically fixed due to stronger sexual selection on males. Instead, sex differences in life-history and/or the strength of sexual selection may cause sex differences, not in the degree of ornamentation, but on the extent that investment in ornamentation is plastic and dependent on ecological conditions.

\section{Methods}

\section{Diet experiment}

\section{Housing and diet manipulations}

This experiment took place in a research aviary at the Research Centre in Biodiversity and Genetic Resources (CIBIO-InBio), University of Porto, Portugal, and lasted 14 weeks, from the $23^{\text {rd }}$ July until the $29^{\text {th }}$ October 2018. Common waxbills (Estrilda astrild) were acquired from certified breeders in March 2018, approximately four months before the experiment. We used 23 birds, 11 males and 12 females, all ringed with individually numbered metal rings and housed in mixed-sex groups in six metal cages (88.5 $\mathrm{x}$ $30 \times 40 \mathrm{~cm}$ ). Each cage housed two males and two females (except one cage with one male and two females). The cages were in an outdoor aviary, sheltered from wind and direct sunlight, and with natural illumination supplemented with artificial lights in the same dial cycle as the natural light. One of the aviary walls was made of metal grid so that the temperature and humidity inside the aviary were identical to outside conditions. Each cage had four long perches, sand in the floor, ad libitum water in two dispensers (changed every other day) and food (Tropical Finches Prestige, Versele-Laga) in two long feeders that allowed all birds to feed simultaneously. A bathtub filled with water was placed inside the cages for birds to bath twice a week. All experimental protocols were carried out in accordance with relevant guidelines and regulations, and were approved by the ORBEA (Organism for Animal Welfare) of CIBIO-InBIO (ethics assessment \# ORBEA_2019_Estrilda).

During the 14 weeks of the experiment, we performed diet manipulations in a balanced manner across cages. Each of three different treatments - control, lutein-supplemented and vitamin E-supplemented was administered to two bird cages for four weeks, then there was an interval of one week with standard control diet, for the following 4-weeks period the treatments were rotated (cages that had had control diets now were lutein-supplemented, those that had had lutein now were vitamin E-supplemented, and 
those that had had vitamin E now had control diets) and, after another one-week interval, for the last 4weeks period the treatments rotated again, so that all cages experienced the three diet treatments.

We manipulated carotenoid and the vitamin E content by adding either lutein or vitamin $\mathrm{E}$ to the drinking water, while in control diets nothing was added to the water. Concentrations were $4 \mathrm{~g} / \mathrm{l}$ of lutein (FloraGlo, $10 \%$ ), and $1.8 \mathrm{~g} / \mathrm{l}$ of vitamin E (A.C. Grace, Unique E Natural Vitamin E Oil). Since common waxbills do not drink much water ${ }^{60}$, and following experiments on other bird species, we chose the above dosages so as to administer ca. $0.2 \mathrm{mg}$ lutein per day per bird 37,61 and ca. $0.9 \mathrm{mg}$ vitamin $\mathrm{E}$ per day per bird ${ }^{29,38}$. By comparison, the amount of carotenoid and vitamin E obtained from the commercial mixture of seeds should be very small. Birds had ad libitum access to a commercial mixture of seed with the following composition: canary seed $40 \%$, panicum yellow $28 \%$, yellow millet $15 \%$, Japanese millet $10 \%$, panicum red $6 \%$ and perilla seed $1 \%$ (Tropical Finches, Australian Finches, Versele-Laga). The most abundant seed in this mixture, canary seed, has a low carotenoid concentration of $2.8 \mu \mathrm{g} / \mathrm{g}^{62}$ and a low antioxidant capacity ${ }^{63}$. Throughout the 4-week periods of diet manipulations, food and water were replenished every other day to ensure fresh supplements.

\section{Bill color measurements and body weight}

We measured bill color saturation a total of fifteen times during the experiment, starting in the first day of experiments, on the $23^{\text {rd }}$ July, and then weekly until the end of experiments, on the $29^{\text {th }}$ October 2018 . We used reflectance spectrophotometry, with an Ocean Optics usb4000 spectrophotometer coupled to a PX-2 xenon light source, and calibrated $0 \%$ and $100 \%$ reflectance of measurements with an opaque black velvet and an Ocean Optics WS-1-SL white standard, respectively. Measurements were made with the reflectance probe gently touching perpendicularly the bill surface, and then enveloping the area with black velvet to prevent light contamination from outside the probe. Each time we measured four spectra from the bill, two on each side of the upper mandible, because the upper mandible is the most visible part of the bill. We weighted birds with a spring balance to the nearest $0.05 \mathrm{~g}$ at the beginning and the end of each 4-week period of the experiment at the same time of the color measurements, in the mornings.

We flattened reflectance below $1 \%$ to $1 \%$, because small measurement inaccuracies near $0 \%$ reflectance are large in relative terms, and then $\log _{10}$-transformed reflectance spectra to quantify reflectance in a ratio scale, which conforms to the mechanisms of color production and perception ${ }^{64}$. As in Funghi et al. ${ }^{13}$, we computed bill color saturation by averaging $\log _{10}$-reflectance across the wavelengths at which the reflectance of red bills plateaus and is highest $(600$ and $700 \mathrm{~nm})$, and then subtracting the average $\log _{10^{-}}$ reflectance across the entire bird-visible range of wavelengths $\left(320-700 \mathrm{~nm}^{65}\right.$; note that differences of logarithms quantify ratios of raw measurements). We averaged color saturation for the four bill spectra of each bird, in each day.

\section{Statistical analyses}


During the 4-week periods of diet supplementations, we observed that bill color saturation on average showed a plateau after week 2 (Fig. S1). Therefore, in statistical models we used as dependent variable the mean color saturation in weeks 2 to 4 from each 4-week period. For each sex, we ran General Mixed Models (GLMM) with bill color saturation as dependent variable, individual identity as random factor, diet treatment as a 3-level factor (control, lutein, vitamin E), time point as a 2-level factor (before or after diet manipulation), and the interaction between diet treatment and time point. The result of interest is the interaction effect, which tests if changes in bill color saturation from before to after the diet manipulation differ among diet treatments. As post-hoc tests, we ran identical GLMM but with diet treatment as a 2level factor (either control vs. lutein, or control vs. vitamin E).

A concern in this experiment is that, although there were one-week intervals between the different diet treatments, there may be carry-over effects of one treatment on the bill color saturation at the onset of the following treatment (i.e., effects of lutein supplementation extending to the beginning of the vitamin $E$ treatment that follows it, or effects of vitamin E supplementation extending to the beginning of the control treatment that follows it). Therefore, to prevent possible carry-over effects from influencing analyses, we also run a GLMM using the measurements from the lutein or vitamin $\mathrm{E}$ diet treatments (average of weeks 2 to 4 , as before) and, instead of the control treatment, the first bill color measurement made at the beginning of the experiment, before any diet manipulation was made. In this GLMM, bill color saturation is the dependent variable, individual identity is a random factor, and diet treatment is a 3-level factor (beginning, lutein, vitamin E).

For body weight, similarly to the main color analysis, we performed a GLMM with body weight as dependent variable, individual identity as random factor, diet treatment (control, lutein, vitamin E) and time point (before or after diet manipulation) as factors, and the interaction between diet treatment and time point. Again, the result of interest is the interaction effect, which tests if weight changed differently between treatments.

\section{Temperature experiment}

\section{Housing and temperature manipulation}

This experiment took place in the same aviary as before, and lasted for 10 weeks, from the $10^{\text {th }}$ December 2018 to the $20^{\text {th }}$ February 2019, during the coldest months of the year. The waxbills used in this experiment were the same as in the previous experiment, except for one male that was added and one female that had died in the meantime, thus resulting in 12 males and 11 females. Birds were kept in mixed-sex groups throughout the experiment (two males and two females per cage, except one cage with two males and one female), and housing conditions were as described before.

Three of the bird cages received a cold-hot treatment, consisting of cold temperature (ambient temperature) for 4 weeks, then a two-week interval, and hot temperature (heated cages) for other 4 weeks. The other three cages received the reverse treatment, hot-cold: hot temperature during the first 4 weeks, a two-week interval without heaters, and then cold temperature during the final 4 weeks. Four-week periods 
of temperature manipulation were previously shown sufficient to change bill color in zebra finches (Taeniopygia guttata $\left.{ }^{11}\right)$. We heated cages by placing two warming devices $(24 \times 27.5 \times 7 \mathrm{~cm}$ electric foot warmers, Junex model 5768 , consisting of a $70 \mathrm{~W}$ warming plate protected by wooden frames) below each cage. In addition, the top $26 \mathrm{~cm}$ of the front grid of all cages was covered with transparent cling film, to retain warm air within the cage, and a $7 \mathrm{~cm}$-high area in the bottom of the cage remained without cling film for aeration. The sides, back and top of each cage, made of metal, were covered on the outside by Styrofoam plates to further retain heat (Fig. S2). For the onset of the hot treatment to be gradual, we turned on the warming devices on the first day of each 4-week period but did not immediately apply the cling film, which we then applied to all six cages (both heated or at ambient temperature) two days afterwards. In this manner, we could manipulate temperature differently across cages in the same shared environment, without having to isolate or move some of the birds to different rooms.

Each cage had a data logger (Elitech RC-5 USB Temperature Data Logger) hanging from the top of the cage, at the center, recording temperatures every 30 minutes. Another temperature logger, located outside the cages in the aviary, also recorded temperature every 30 minutes. Throughout the experiment, the cold cages had the same temperature as outside in the aviary, and the temperature differences between these and the hot cages remained stable, averaging $5.7^{\circ} \mathrm{C}\left( \pm 0.7^{\circ} \mathrm{C}\right.$ SD; Fig. S3). Data loggers inside the cages failed to record temperatures during the second week of the experiments, and we replaced the missing data from that week by measurements from the external temperature logger plus the mean difference between temperatures inside and outside the cages, recorded during the remaining of the experiment (mean difference was $6.444^{\circ} \mathrm{C}$ for the heated cages, and $0.679^{\circ} \mathrm{C}$ for the ambient temperature cages). These reconstructed temperatures are represented by dashed lines in figure S3.

\section{Feeding, bill color measurements and body weight}

We set up a video system in the aviary room (two HP HD 2300 webcams connected to a computer) to automatically record the behavior of the birds early in the morning, from half an hour before sunrise until two hours later, on every Saturday, when there was no disturbance due to maintenance of the aviary. Videos were analyzed by the same person (R.F.), using instantaneous observations at every two minutes along the two hours of video, and noting how many birds were feeding (i.e., at a feeder or at less than one body of distance behind the feeders). We calculated an index of feeding in each cage, as the average number of birds feeding during the two hours of observation.

We measured bill coloration in males and females throughout the experiment at eight time points: once at the end of each week of the two 4-week temperature manipulation periods (Fig. S3). Measurements were taken always at ca. 2 p.m., first on the day when each 4-week temperature treatment began (before turning on the heating devices), and then once a week for the following four weeks of each period. Color was measured using reflectance spectrophotometry, in the same way described above. We weighted birds with a spring balance to the nearest $0.05 \mathrm{~g}$, by the end of each part of the experiment ( $9^{\text {th }}$ January and $20^{\text {th }}$ February) at the same time of the final color measurements. 


\section{Statistical analyses}

We computed changes in feeding, in body weight and in bill color saturation as the difference between measurements in last and the first 4-week periods. We then tested how temperature manipulation affected changes in these traits by comparing birds in the cold-hot and the hot-cold treatments with independent samples t-tests. In this way, and since the cold-hot and hot-cold treatments took place simultaneously, we test effects of temperature while controlling for longitudinal changes unrelated to the temperature manipulation. For comparing changes in feeding we used as statistical unit each of the cages (since observations of feeding were at the level of cages rather than individuals), and for comparing changes in body weight we used individuals as statistical units.

To test effects of the temperature manipulation on bill color saturation we ran t-tests separately for males and females, and we computed changes in color saturation in two different manners. First, we computed changes as the mean saturation across all measurements of the same individual in the last 4 weeks of the experiment minus the mean saturation across all its measurements in the first 4 weeks. Second, and in case bill color takes a long time to change in response to temperature, we computed change as above but using only measurements from the last 2 weeks of each 4-week period. Additionally, we also tested if temperature manipulation affected the extent of fluctuation or stability in bill color saturation. For this, we computed changes in bill color fluctuation for each individual as the difference between the standard deviation of measurements in the last 4 weeks of the experiment minus the standard deviation of measurements in the first 4 weeks.

\section{Declarations}

\section{Acknowledgments}

We are grateful to Kemin Portugal for providing the lutein (FloraGLo) used in this study. This work was supported by Fundação para a Ciência e a Tecnologia (FCT) (project PTDC/BIA-ECO/32210/2017) and Portuguese National Funds through FCT (DL57/2016/CP1440/CT0011).

\section{Author contributions}

S.T. and G.C.C. designed the experiments; R.F., C.M. and S.T. performed experiments and quantified data; R.F., S.T. and G.C.C. analyzed the data; R.F. and S.T. wrote the manuscript with contributions from all authors.

\section{Competing interest statement}

The authors declare no competing interests.

\section{References}

1. Darwin, C. The descent of man, and selection in relation to sex. London: Jon Murray (1871). 
2. Andersson, M. Sexual selection. Princeton: Princeton University Press. (1994).

3. McGraw, K. J. \& Ardia, D. R. Carotenoids, immunocompetence, and the information content of sexual colors: an experimental test. Nat. 162, 704-712 (2003).

4. Clutton-Brock, T. Sexual selection in females. Animal Behav. 77, 3-11 (2009).

5. West-Eberhard, M. J. Sexual selection, social competition, and speciation. Rev. Biol. 58, 155-183 (1983).

6. Lyon, B.E. \& Montgomerie, R. Sexual selection is a form of social selection. Trans. R. Soc. B 367, 2266-2273 (2012).

7. Faivre, B., Grégoire, A., Préault, M., Cézilly, F. \& Sorci, G. Immune activation rapidly mirrored in a secondary sexual trait. Science 300, 103 (2003).

8. Gautier, P. et al. The presence of females modulates the expression of a carotenoid-based sexual signal. Ecol. Sociobiol. 62, 1159-1166 (2008).

9. Hill, G. E., Hood, W. R. \& Huggins, K. A multifactorial test of the effects of carotenoid access, food intake and parasite load on the production of ornamental feathers and bill coloration in American goldfinches. Exp. Biol. 212, 1225-1233 (2009).

10. Rosenthal, M. F., Murphy, T. G., Darling, N. \& Tarvin, K. A. Ornamental bill color rapidly signals changing condition. Avian Biol. 43, 553-564 (2012).

11. Eraud, C. et al. Environmental stress affects the expression of a carotenoid-based sexual trait in male zebra finches. Exp. Biol. 210, 3571-3578 (2007).

12. Kelly, R. J., Murphy, T. G., Tarvin, K. A. \& Burness, G. Carotenoid-based ornaments of female and male American goldfinches (Spinus tristis) show sex-specific correlations with immune function and metabolic rate. Biochem. Zool. 85, 348-363 (2012).

13. Funghi, C., Trigo, S., Gomes, A. C. R., Soares, M. C. \& Cardoso, G. C. Release from ecological constraint erases sex difference in social ornamentation. Ecol. Sociobiol. 72, (2018).

14. DeWitt, T. J., Sih, A. \& Wilson, D. S. Costs and limits of phenotypic plasticity. TREE 13, 77-81 (1998).

15. West-Eberhard, M. J. Developmental plasticity and evolution. New York: Oxford University Press, (2003).

16. Weaver, R. J., Santos, E. S. A., Tucker, A. M., Wilson, A. E. \& Hill, G. E. Carotenoid metabolism strengthens the link between feather coloration and individual quality. Commun. 9, 73 (2018).

17. von Schantz, T., Bensch, S., Grahn, M., Hasselquist, D. \& Wittzell, H. Good genes, oxidative stress and condition-dependent sexual signals. Biol. Sci. 266, 1-12 (1999).

18. Møller, A. P. et al. Carotenoid-dependent signals: indicators of foraging efficiency, immunocompetence or detoxification ability? Avian Poult. Biol. Rev. 11, 137-159 (2000).

19. Garratt, M. \& Brooks, R. C. Oxidative stress and condition-dependent sexual signals: more than just seeing red. Biol. Sci. 279, 3121-3130 (2012).

20. Simons, M. J. P., Cohen, A. A. \& Verhulst, S. What does carotenoid-dependent coloration tell? Plasma carotenoid level signals immunocompetence and oxidative stress state in birds-a meta-analysis. 
PLoS One 7, (2012).

21. Hõrak, P., Ots, I., Vellau, H., Spottiswoode, C. \& Møller, A. P. Carotenoid-based plumage coloration reflects hemoparasite infection and local survival in breeding great tits. Oecologia 126, 166-173 (2001).

22. Clement, P., Harris, A. \& Davies, J. Finches and sparrows: an identification guide. Princeton: Princeton University Press (1993).

23. Cardoso, G. C., Batalha, H. R., Reis, S. \& Lopes, R. J. Increasing sexual ornamentation during a biological invasion. Ecol. 25, 916-923 (2014a).

24. Cardoso, G. C. et al. Similar preferences for ornamentation in opposite- and same-sex choice experiments. Evol. Biol. 27, 2798-2806 (2014b).

25. Funghi, C., Leitão, A. V., Ferreira, A. C., Mota, P. G. \& Cardoso, G. C. Social dominance in a gregarious bird is related to body size but not to standard personality assays. Ethology 121, 84-93 (2015).

26. Navara, K. J. \& Hill, G. E. Dietary carotenoid pigments and immune function in a songbird with extensive carotenoid-based plumage coloration. Ecol. 14, 909-916 (2003).

27. McGraw, K. J. \& Schuetz, J. G. The evolution of carotenoid coloration in estrildid finches: A biochemical analysis. Biochem. Physiol. - B Biochem. Mol. Biol. 139, 45-51 (2004).

28. Karu, U., Saks, L. \& Hõrak, P. Carotenoid-based plumage coloration is not affected by vitamin E supplementation in male greenfinches. Res. 23, 931-935 (2008).

29. Pérez, C., Lores, M. \& Velando, A. Availability of nonpigmentary antioxidant affects red coloration in gulls. Ecol. 19, 967-973 (2008).

30. Hartley, R. C. \& Kennedy, M. W. Are carotenoids a red herring in sexual display? TREE 19, $353-354$ (2004).

31. Alonso-Alvarez, C. et al. An experimental test of the dose-dependent effect of carotenoids and immune activation on sexual signals and antioxidant activity. Nat. 164, 651-659 (2004).

32. Jouventin, P., McGraw, K. J., Morel, M. \& Célerier, A. Dietary carotenoid supplementation affects orange beak but not foot coloration in gentoo penguins Pygoscelis papua. Waterbirds 30, 573-578 (2007).

33. Saino, N. et al. Better red than dead: carotenoid-based mouth coloration reveals infection in barn swallow nestlings. Biol. Sci. 267, 57-61 (2000).

34. Thorogood, R., Kilner, R. M., Karadaş, F. \& Ewen, J. G. Spectral mouth color of nestlings changes with carotenoid availability. Ecol. 22, 1044-1051 (2008).

35. Koch, R., Wilson, A. \& Hill, G. The importance of carotenoid dose in supplementation studies with songbirds. Biochem. Zool. 89, 61-71 (2015).

36. Hill, G. E. Proximate basis of variation in carotenoid pigmentation in male House Finches. The Auk 109, 1-12 (1992).

37. Biard, C., Surai, P. F. \& Møller, A. P. Carotenoid availability in diet and phenotype of blue and great tit nestlings. Exp. Biol. 209, 1004-1015 (2006). 
38. Giraudeau, M., Sweazea, K., Butler, M. W. \& McGraw, K. J. Effects of carotenoid and vitamin E supplementation on oxidative stress and plumage coloration in house finches (Haemorhous mexicanus). Biochem. Physiol. - A Mol. Integr. Physiol. 166, 406-413 (2013).

39. Goodwin, T. W. Distribution of carotenoids. Method Enzymol. 213, 167-172 (1992).

40. Hill, G. E. Female house finches prefer colourful males: sexual selection for a condition-dependent trait. Anim Behav. 40, 563-572 (1990).

41. Olson, V. A. \& Owens, I. P. F. Costly sexual signals: are carotenoids rare, risky or required? TREE 13, 510-514 (1998).

42. Koch, R. E. \& Hill, G. E. Do carotenoid-based ornaments entail resource trade-offs? An evaluation of theory and data. Ecol. 32, 1908-1920 (2018).

43. Krinsky, N. I. Carotenoids as antioxidants. Nutrition 17, 815-817 (2001).

44. El-Agamey, A. et al. Carotenoid radical chemistry and antioxidant/pro-oxidant properties. Biochem. Biophys. 430, 37-48 (2004).

45. Costantini, D. 6 Møller, A. P. Carotenoids are minor antioxidants for birds. Ecol. 22, 367-370 (2007).

46. Leclaire, S. et al. Carotenoids increase immunity and sex specifically affect color and redox homeostasis in a monochromatic seabird. Ecol. Sociobiol. 69, 1097-1111 (2015).

47. Benito, M., González-Solís, J. \& Becker, P. H. Carotenoid supplementation and sex-specific trade-offs between colouration and condition in common tern chicks. Comp. Physiol. B 181, 539-549 (2011).

48. Surai, P. F. Natural antioxidants in avian nutrition and reproduction. Nottingham, United Kingdom: Nottingham University Press (2002).

49. Bertrand, S., Faivre, B. \& Sorci, G. Do carotenoid-based sexual traits signal the availability of nonpigmentary antioxidants? Exp. Biol. 209, 4414-4419 (2006).

50. Marri, V. \& Richner, H. Differential effects of vitamins E and C and carotenoids on growth, resistance to oxidative stress, fledging success and plumage colouration in wild great tits. Exp. Biol. 217, 14781484 (2014).

51. Kopena, R., López, P. \& Martín, J. Relative contribution of dietary carotenoids and vitamin E to visual and chemical sexual signals of male Iberian green lizards: an experimental test. Ecol. Sociobiol. 68, 571-581 (2014).

52. Pike, T. W., Blount, J. D., Lindström, J. \& Metcalfe, N. B. Availability of non-carotenoid antioxidants affects the expression of a carotenoid-based sexual ornament. Lett. 3, 353-356 (2007).

53. Sanz-Aguilar, A., Carrete, M., Edelaar, P., Potti, J. \& Tella, J. L. The empty temporal niche: breeding phenology differs between coexisting native and invasive birds. Invasions 17, 3275-3288 (2015).

54. Pan, J. Q., Tan, X., Li, J. C., Sun, W. D. \& Wang, X. L. Effects of early feed restriction and cold temperature on lipid peroxidation, pulmonary vascular remodelling and ascites morbidity in broilers under normal and cold temperature. Poultry Sci. 46, 374-381 (2005).

55. Zhang, Z. W. et al. Effects of cold stress on nitric oxide in duodenum of chicks. Poultry Sci. 90, 15551561 (2011). 
56. Beaulieu, M., Haas, A. \& Schaefer, M. H. Self-supplementation and effects of dietary antioxidants during acute thermal stress. Exp. Biol. 217, 370-375 (2013).

57. Stier, A., Massemin, S. \& Criscuolo, F. Chronic mitochondrial uncoupling treatment prevents acute cold-induced oxidative stress in birds. Comp. Physiol. B 184, 1021-1029 (2014).

58. Beamonte-Barrientos, R. \& Verhulst, S. Plasma reactive oxygen metabolites and non-enzymatic antioxidant capacity are not affected by an acute increase of metabolic rate in zebra finches. Comp. Physiol. B 183, 675-683 (2013).

59. Moreno, J., Cantarero, A., Plaza, M. \& López-Arrabé, J. Phenotypic plasticity in breeding plumage signals in both sexes of a migratory bird: responses to breeding conditions. Avian Biol. 50, (2019).

60. del Hoyo, J., Elliott, A. \& Sargatal, J. Handbook of the Birds of the World. Vol. 15: Weavers to New World Warblers. Lynx Edicions, Barcelona (2010).

61. Larcombe, S. D., Mullen, W., Alexander, L. \& Arnold, K. E. Dietary antioxidants, lipid peroxidation and plumage colouration in nestling blue tits Cyanistes caeruleus. Naturwissenschaften 97, 903-913 (2010).

62. Hudon, J. Showiness, carotenoids, and captivity: a comment on Hill (1992). The Auk 111, 218-221 (1994).

63. Dykes, L. \& Rooney, L. W. Sorghum and millet phenols and antioxidants. Cereal Sci. 44, 236-251 (2006).

64. Cardoso, G. C. \& Gomes, A. C. R. Using reflectance ratios to study animal coloration. Biol. 42, 387394 (2015).

65. Montgomerie, R. Analyzing colors. Analyzing colors. In: Hill, G. E., McGraw, K. J., editors. Bird coloration, volume 1, mechanisms and measurements. Cambridge, MS: Harvard University Press. p. 90-147 (2006).

\section{Figures}



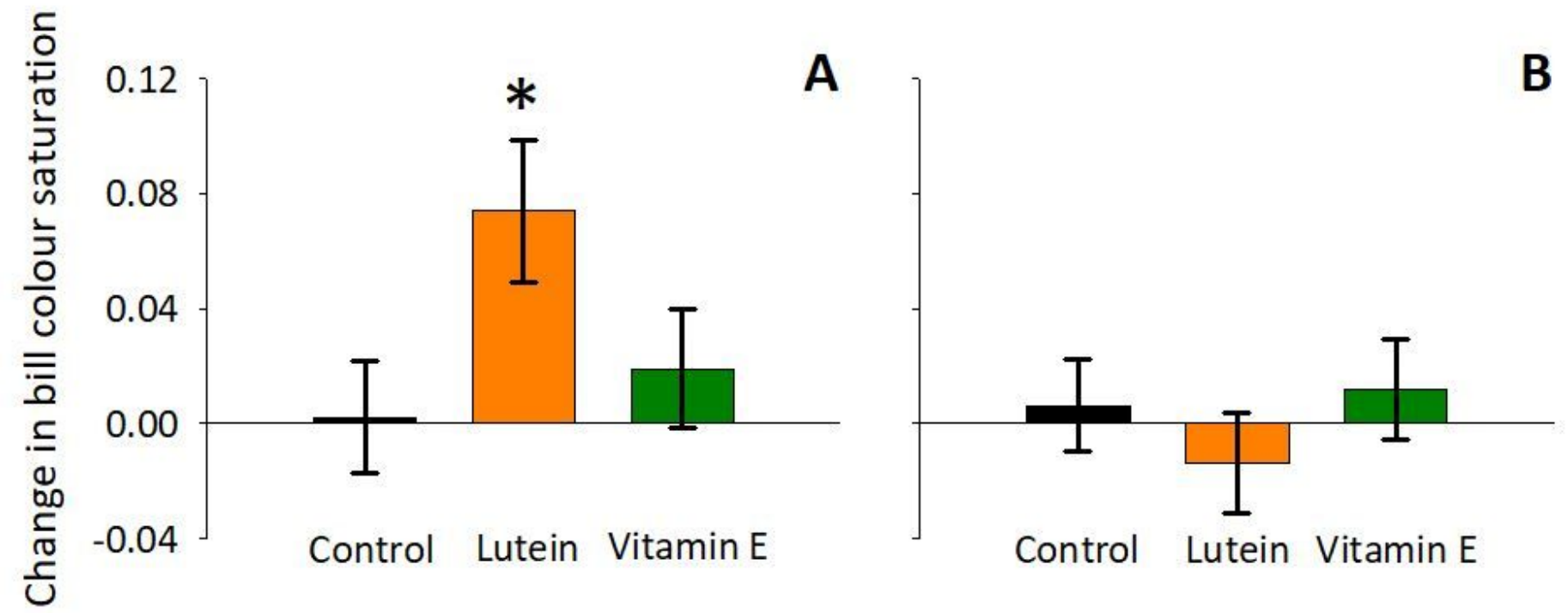

Figure 1

Changes in (A) female and (B) male bill color saturation (mean \pm SE) from before to after each diet manipulation (control in black, lutein-supplemented in orange, and vitamin E-supplemented in green). Asterisks mark statistically significant differences in post-hoc tests against the control treatment.

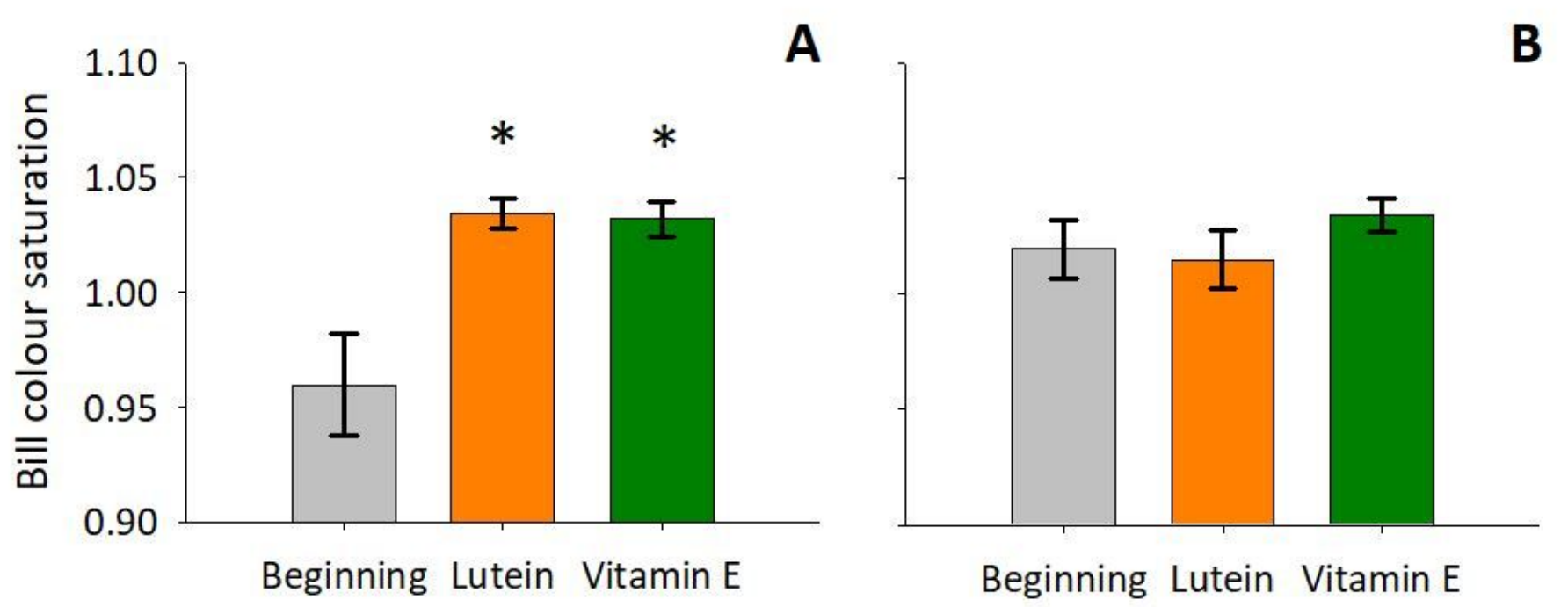

Figure 2

(A) Female and (B) male bill color saturation (mean \pm SE) before any diet manipulation (grey), and after each 4-week diet supplementation treatment (colors as in Figure 1). Asterisks mark statistically significant differences between measurements after diet supplementation and measurements before any diet manipulation. 


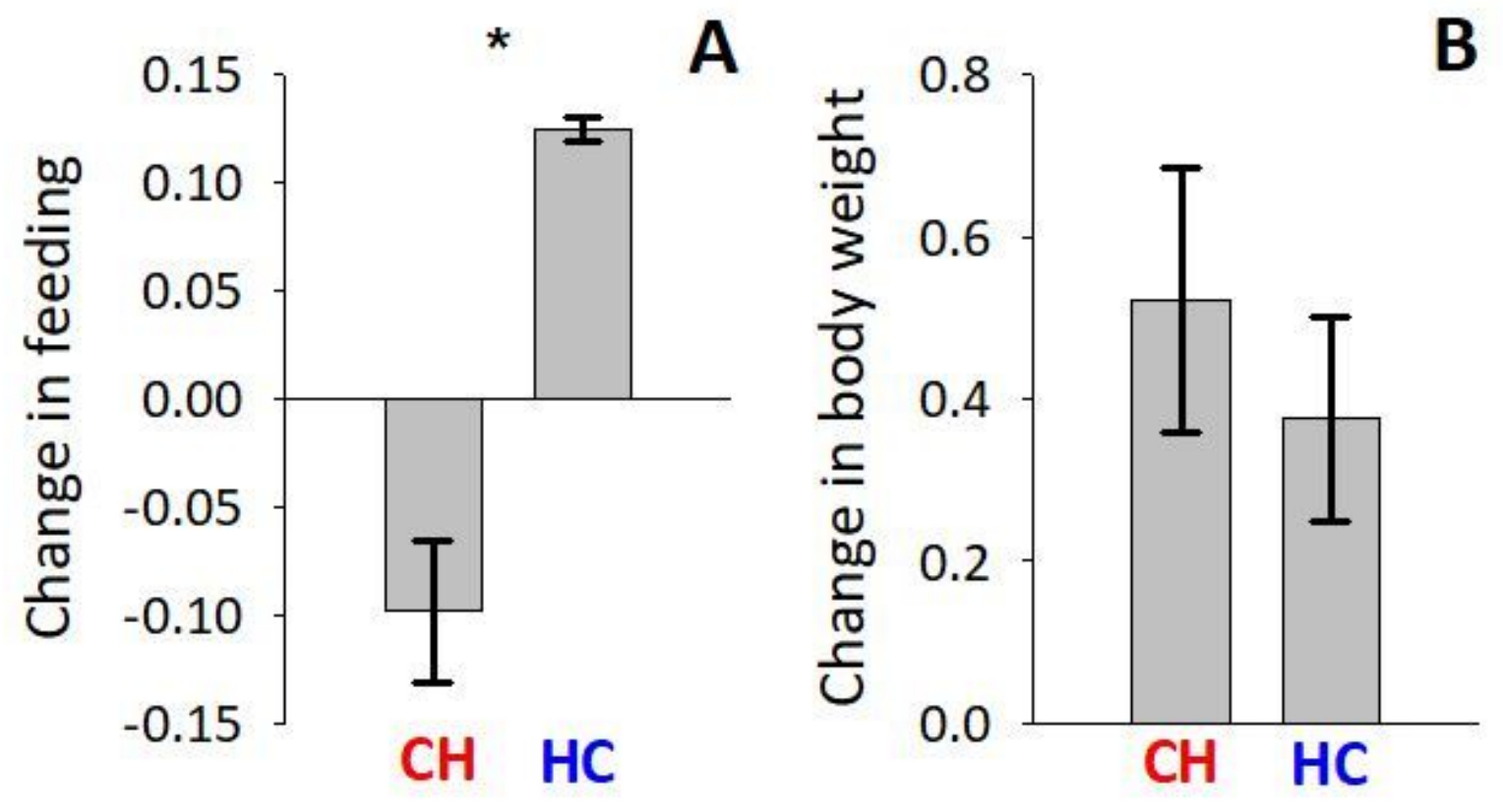

Figure 3

Changes (mean $\pm \mathrm{SE}$ ) in $(\mathrm{A})$ feeding and $(\mathrm{B})$ body weight $(\mathrm{g})$ during the two temperature treatments. $\mathrm{CH}$ : cold-hot treatment; HC: hot-cold treatment. Asterisks mark statistically significant differences. 

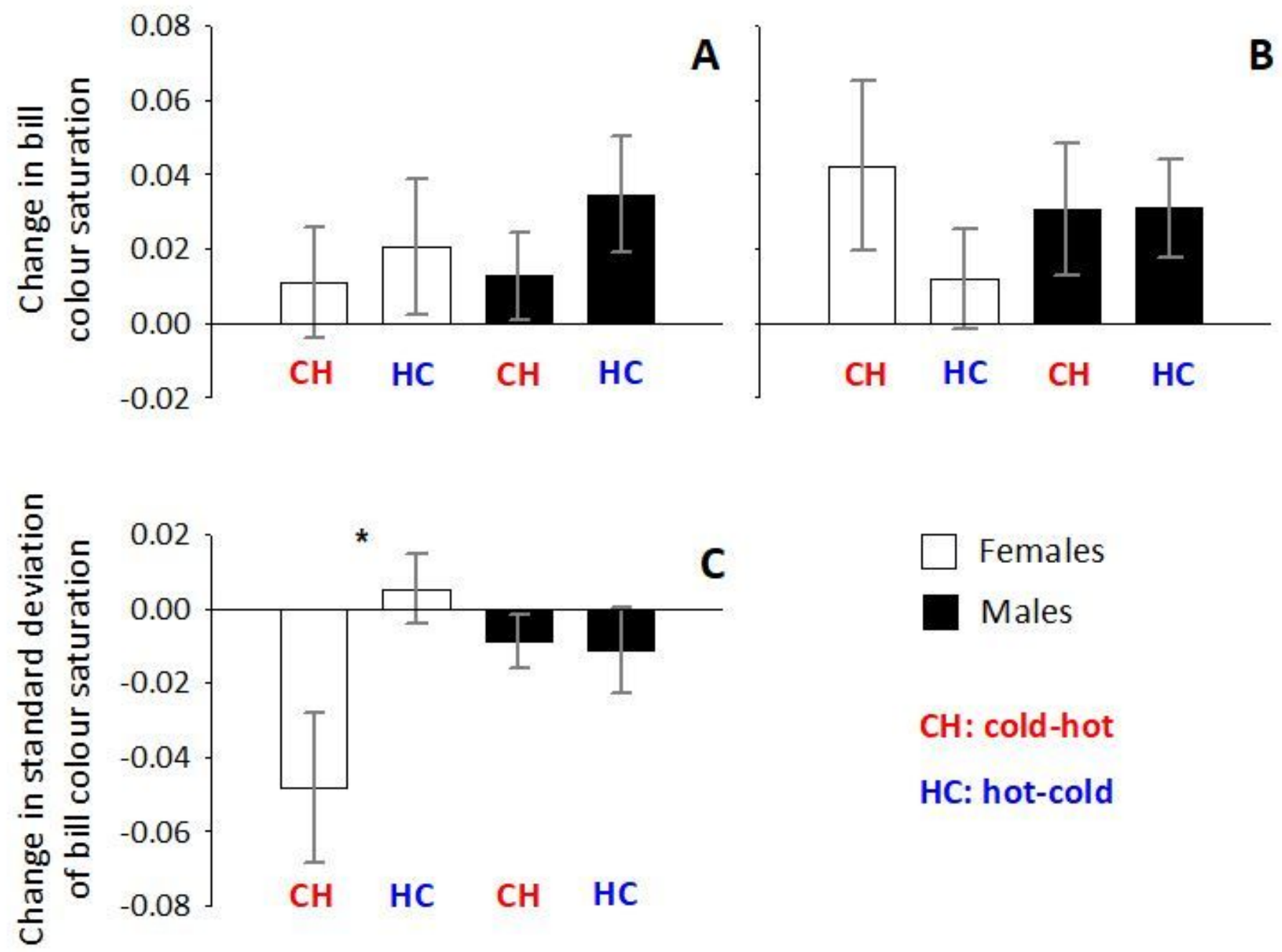

Figure 4

Changes in bill color saturation (means \pm SE) using data from (A) the entire 4-week periods of temperature manipulations, or (B) the last 2 weeks of each 4-week period temperature manipulations. (C) Changes in the standard deviation of bill color saturation. $\mathrm{CH}$ : cold-hot treatment; $\mathrm{HC}$ : hot-cold treatment. Asterisks mark statistically significant differences between treatments.

\section{Supplementary Files}

This is a list of supplementary files associated with this preprint. Click to download.

- SupplementaryInformation.docx 